\title{
APÊNDICE B \\ OS CRITÉRIOS DIAGNÓSTICOS DE ROMA III PARA OS DISTÚRBIOS GASTROINTESTINAIS FUNCIONAIS
}

\section{A. DISTÚRBIOS ESOFÁGICOS FUNCIONAIS}

\section{A1. Pirose funcional}

Os critérios* diagnósticos devem incluir todos os itens a seguir:

1. Queimação ou dor retroesternal;

2. Falta de evidência de que o refluxo gastroesofágico é a causa do sintoma;

3. Ausência de distúrbios da motilidade esofágica baseados em alterações histopatológicas.

* Critérios preenchidos nos últimos 3 meses com início dos sintomas pelo menos 6 meses antes do diagnóstico.

\section{A2. Dor torácica funcional de presumível origem esofágica}

Os critérios* diagnósticos devem incluir todos os itens a seguir:

1. Dor ou desconforto retroesternal que não é em queimação;

2. Falta de evidência de que o refluxo gastroesofágico é a causa do sintoma;

3. Ausência de distúrbios da motilidade esofágica baseados em alterações histopatológicas.

* Critérios preenchidos nos últimos 3 meses com início dos sintomas pelo menos 6 meses antes do diagnóstico.

\section{A3. Disfagia funcional}

Os critérios* diagnósticos devem incluir todos os itens a seguir:

1. A percepção da passagem dos alimentos, líquidos ou sólidos, ao longo do esôfago. Na linguagem do paciente pode ser referido como alimento que tranca, fica retido ou passa com dificuldade;

2. Falta de evidência de que o refluxo gastroesofágico é a causa do sintoma;
3. Ausência de distúrbios da motilidade esofágica baseados em alterações histopatológicas.

* Critérios preenchidos nos últimos 3 meses com início dos sintomas pelo menos 6 meses antes do diagnóstico.

\section{A4. Globus}

Os critérios* diagnósticos devem incluir todos os itens a seguir:

1. Sensação não dolorosa persistente ou intermitente de presença de um nó ("bola"ou "bolo") ou de um corpo estranho na garganta;

2. Ocorrência da sensação entre as refeições;

3. Ausência de disfagia ou de odinofagia;

4. Falta de evidência de que o refluxo gastroesofágico é a causa do sintoma;

5. Ausência de distúrbios da motilidade esofágica baseados em alterações histopatológicas.

* Critérios preenchidos nos últimos 3 meses com início dos sintomas pelo menos 6 meses antes do diagnóstico.

\section{B. DISTÚRBIOS GASTRODUODENAIS FUNCIONAIS}

\section{B1. Dispepsia funcional}

Os critérios* diagnósticos devem incluir todos os itens a seguir:

1. Um ou mais dos itens a seguir:

a. sensação incômoda de plenitude pós-prandial;

b. saciedade precoce

c. dor epigástrica

d. queimação epigástrica

2. Nenhuma evidência de doença estrutural (presente na endoscopia do trato digestivo superior) que seja capaz de explicar os sintomas

* Critérios preenchidos nos últimos 3 meses com início dos sintomas pelo menos 6 meses antes do diagnóstico. 


\section{B1a. Síndrome do desconforto pós-prandial}

Os critérios* diagnósticos devem incluir um ou ambos os itens a seguir:

1. Sensação incômoda de plenitude pós-prandial que ocorre após refeições habituais, pelo menos várias vezes na semana;

2. Saciedade precoce que impede finalizar uma refeição comum, pelo menos várias vezes na semana.

* Critérios preenchidos nos últimos 3 meses com início dos sintomas pelo menos 6 meses antes do diagnóstico.

\section{Critérios de apoio}

1. Empachamento/estufamento abdominal superior ou náusea pós-prandial ou eructação excessiva podem estar presentes;

2. Síndrome da dor epigástrica pode coexistir.

\section{B1b. Síndrome da dor epigástrica}

Os critérios* diagnósticos devem incluir todos os itens a seguir:

1. Dor ou queimação localizada no epigástrio com intensidade moderada, pelo menos uma vez por semana;

2. A dor é intermitente;

3. Não é generalizada ou localizada para outras regiões do abdome ou do tórax;

4. Não é aliviada com a defecação ou por flatulência;

5. Não preenche os critérios para os distúrbios da vesícula e do esfíncter de Oddi.

* Critérios preenchidos nos últimos 3 meses com início dos sintomas pelo menos 6 meses antes do diagnóstico.

\section{Critérios de apoio}

1. A dor pode ser em queimação, mas sem um componente retroesternal;

2. A dor é comumente induzida ou aliviada pelas refeições, mas pode ocorrer também durante o jejum;

3. A síndrome do desconforto pós-prandial pode coexistir

\section{B2. Distúrbios da eructação}

\section{B2a. Aerofagia}

Os critérios* diagnósticos devem incluir todos os itens a seguir:

1. Aerofagia repetitiva e incômoda pelo menos várias vezes na semana;

2. Engolir o ar de modo que possa ser objetivamente observado ou medido.

* Critérios preenchidos nos últimos 3 meses com início dos sintomas pelo menos 6 meses antes do diagnóstico.

\section{B2b. Eructação excessiva inespecífica}

Os critérios* diagnósticos devem incluir todos os itens a seguir:

1. Aerofagia repetitiva e incômoda pelo menos várias vezes na semana;

2. Não há evidências de que engolir ar em excesso seja a causa do sintoma.

* Critérios preenchidos nos últimos 3 meses com início dos sintomas pelo menos 6 meses antes do diagnóstico.

\section{B3. Distúrbios da náusea e do vômito}

\section{B3a. Náusea idiopática crônica}

Os critérios* diagnósticos devem incluir todos os itens a seguir:

1. Náusea significativa, ocorrendo pelo menos algumas vezes na semana;

2. Habitualmente não está associada com vômito;

3. Ausência de anormalidades na endoscopia digestiva superior ou doença metabólica que explique a náusea.

* Critérios preenchidos nos últimos 3 meses com início dos sintomas pelo menos 6 meses antes do diagnóstico.

\section{B3b. Vômito funcional}

Os critérios* diagnósticos devem incluir todos os itens a seguir:

1. Cerca de um ou mais episódios de vômito por semana;

2. Ausência de critério para distúrbio alimentar, ruminação ou distúrbio psiquiátrico maior de acordo com o DSM-IV;

3. Ausência de vômito auto-induzido, uso crônico de canabinoide, ausência de anormalidades no sistema nervoso central ou doenças metabólicas que expliquem o vômito recorrente.

* Critérios preenchidos nos últimos 3 meses com início dos sintomas pelo menos 6 meses antes do diagnóstico.

\section{B3c. Síndrome do vômito cíclico}

Os critérios* diagnósticos devem incluir todos os itens a seguir:

1. Episódios de vômito que se repetem de forma semelhante, considerando-se o início (agudo) e a duração (menos de 1 semana);

2. Três ou mais episódios distintos no ano anterior;

3. Ausência de náusea e de vômito entre os episódios.

\section{Critérios de apoio}

História ou histórico familiar de dores de cabeça tipo enxaqueca.

\section{B4. Síndrome da ruminação em adultos}

Os critérios* diagnósticos devem incluir todos os itens a seguir:

1. Regurgitação persistente ou recorrente do alimento recém-ingerido à boca, sendo subsequentemente cuspido ou remastigado e engolido;

2. A regurgitação não é precedida por esforço de vômito.

\section{Critérios de apoio}

1. Os episódios de regurgitação geralmente não são precedidos de náusea;

2. Interrupção do processo quando o material regurgitado se torna ácido;

3. A regurgitação contém alimentos que são reconhecidos e cujo sabor é agradável.

* Critérios preenchidos nos últimos 3 meses com início dos sintomas pelo menos 6 meses antes do diagnóstico. 


\section{DISTÚRBIOS INTESTINAIS FUNCIONAIS}

\section{C1. Síndrome do intestino irritável}

Os critérios* diagnósticos devem incluir todos os itens a seguir:

Dor ou desconforto abdominal recorrente** pelo menos 3 dias/mês, nos últimos 3 meses, associada com dois ou mais dos seguintes:

1. Melhora com a defecação;

2. Início associado com mudança na frequência das evacuações;

3. Início associado com mudança no formato (aparência) das fezes.

* Critérios preenchidos nos últimos 3 meses com início dos sintomas pelo menos 6 meses antes do diagnóstico.

** "Desconforto" significa uma sensação desconfortável não descrita como dor.

Recomenda-se que, para uma pessoa possa participar e ser incluida nos protocolos de pesquisas de fisiopatologia e em estudos clínicos, tenha frequência de dor/desconforto de ao menos 2 dias por semana durante o período de avaliação.

\section{C2. Estufamento/Empachamento funcional}

Os critérios* diagnósticos devem incluir os dois itens a seguir:

1. Sensação recorrente de estufamento/empachamento ou distensão visível por pelo menos 3 dias/mês em 3 meses

2. Critérios insuficientes para diagnóstico de dispepsia funcional, síndrome do intestino irritável ou outro distúrbio gastrointestinal funcional

* Critérios preenchidos nos últimos 3 meses com início dos sintomas pelo menos 6 meses antes do diagnóstico.

\section{C3. Constipação funcional}

Os critérios* diagnósticos devem incluir:

1. Dois ou mais dos seguintes:

a. Esforço evacuatório durante pelo menos $25 \%$ das defecações;

b. Fezes grumosas ou duras em pelo menos $25 \%$ das defecações;

c. Sensação de evacuação incompleta em pelo menos $25 \%$ das defecações;

d. Sensação de obstrução/bloqueio anorretal das fezes em pelo menos $25 \%$ das defecações;

e. Manobras manuais para facilitar pelo menos $25 \%$ das defecações (por exemplo, evacuação com ajuda digital, apoio do assoalho pélvico);

f. Menos de três evacuações por semana.

2. Fezes moles estão raramente presentes sem o uso de laxantes;

3. Critérios insuficientes para SII.

* Critérios preenchidos nos últimos 3 meses com início dos sintomas pelo menos 6 meses antes do diagnóstico.

\section{C4. Diarreia funcional}

Critérios diagnósticos*

Fezes moles ou aquosas sem dor, ocorrendo em pelo menos $75 \%$ das evacuações.

* Critérios preenchidos nos últimos 3 meses com início dos sintomas pelo menos 6 meses antes do diagnóstico

\section{C5. Distúrbio intestinal funcional inespecífico}

Critérios diagnósticos*

Sintomas intestinais não atribuíveis a uma etiologia orgânica e que não preenchem critérios para as categorias definidas previamente.

* Critérios preenchidos nos últimos 3 meses com início dos sintomas pelo menos 6 meses antes do diagnóstico.

\section{DOR ABDOMINAL FUNCIONAL}

\section{Síndrome da dor abdominal funcional}

Os critérios* diagnósticos devem incluir todos os itens a seguir:

1. Dor abdominal contínua ou quase contínua;

2. Ausência ou relacionamento somente ocasional de dor com eventos fisiológicos (por exemplo, alimentação, defecação ou menstruação);

3. Alguma diminuição no funcionamento diário;

4. A dor não é dissimulada (por exemplo, fingir-se de doente);

5. Sintomas insuficientes para atingir o critério para outro distúrbio gastrointestinal funcional que explicariam a dor abdominal.

* Critérios preenchidos nos últimos 3 meses com início dos sintomas pelo menos 6 meses antes do diagnóstico.

\section{E. DISTÚRBIOS FUNCIONAIS DA VESÍCULA BILIAR E DO ESFÍNCTER DE ODDI}

\section{E. Distúrbios funcionais da vesícula biliar e do esfíncter de Oddi}

Critérios diagnósticos* devem incluir episódios de dor localizada no epigástrico e/ou quadrante superior direito e todos os seguintes:

1. Episódios com duração de 30 minutos ou mais;

2. Sintomas recorrentes ocorrendo em diferentes intervalos de tempo (não diariamente);

3. A dor aumenta até chegar a um nível que se mantém constante;

4. A dor é de moderada a grave, suficiente para interromper as atividades cotidianas do paciente ou levá-lo a buscar por ajuda em serviço de emergência;

5. A dor não é aliviada pelas evacuações;

6. A dor não é aliviada por alteração postural;

7. A dor não é aliviada com antiácidos;

8. Exclusão de outras doenças estruturais que explicariam os sintomas. 


\section{Critério de apoio}

A dor pode apresentar com um ou mais dos seguintes itens:

1. Estar associada com náusea e vômito;

2. Irradiar para as costas e/ou para a região subescapular direita;

3. Despertar do sono no meio da noite.

\section{E1. Distúrbio funcional da vesícula biliar}

Os critérios* diagnósticos devem incluir todos os itens a seguir:

1. Critério para distúrbio funcional da vesícula biliar e do esfíncter de Oddi;

2. A vesícula biliar está presente;

3. Enzimas hepáticas, bilirrubina conjugada e amilase/lipase normais.

\section{E2. DISTÚRBIO FUNCIONAL DO ESFÍNCTER DE ODDI BILIAR}

Os critérios* diagnósticos devem incluir todos os itens a seguir:

1. Critério para distúrbio funcional do esfíncter de Oddi;

2. Amilase/lipase normais.

\section{Critério de apoio}

Elevação temporária de transaminases, fosfatase alcalina ou bilirrubina conjugada séricas, relacionada a, pelo menos, dois episódios de dor.

\section{E3. Distúrbio funcional do esfíncter de Oddi pancreático}

Os critérios* diagnósticos devem incluir ambos os itens a seguir:

1. Critérios para distúrbios funcionais da vesícula e do esfíncter de Oddi;

2. Amilase/lipase elevadas.

\section{F. DISTÚRBIOS FUNCIONAIS ANORRETAIS}

\section{F1. Incontinência fecal funcional}

Critérios diagnósticos*:

1. Eliminação recorrente e descontrolada de material fecal em indivíduo com desenvolvimento correspondente a, pelo menos, 4 anos de idade associada a um ou mais dos itens a seguir:

a. Funcionamento anormal dos músculos esfincterianos, normalmente enervados e estruturalmente intactos;

b. Discreta anormalidade estrutural e/ou enervação da musculatura esfincteriana;

c. Hábito intestinal normal ou alterado (por exemplo, retenção fecal ou diarréia);

d. Causas psicológicas.

2. Exclusão de todos os itens seguintes:

a. Enervação anormal causada por lesão(ões) no cérebro (por exemplo, demência), na medula espinhal, ou na inervação sacral, ou lesões mistas (por exemplo, esclerose múltipla), ou como parte de neuropatia generalizada periférica ou autonômica (por exemplo, em decorrência de diabetes); b. Anormalidades da função esfincteriana anal associadas com uma doença sistêmica (por exemplo, esclerodermia);

c. Anormalidades estruturais ou neurogênicas creditadas como causa mais importante ou primária da incontinência fecal;

* Critérios preenchidos nos últimos 3 meses.

\section{F2. Dor anorretal funcional}

\section{F2a. Proctalgia crônica}

Os critérios* diagnósticos devem incluir todos os itens a seguir:

1. Dor ou dolorimento retal crônico ou recorrente;

2. Episódios devem durar 20 minutos ou mais;

3. Exclusão de outras causas de dor retal, tais como isquemia, doença inflamatória intestinal, criptite, abscesso intramuscular, fissura anal, hemorroida, prostatite e coccigodínia

* Critérios preenchidos nos últimos 3 meses com início dos sintomas pelo menos 6 meses antes do diagnóstico. A proctalgia crônica deve ser a seguir caracterizada como Síndrome do Elevador do Ânus ou como dor anorretal inespecífica, baseada no exame digital retal.

\section{F2a1. Síndrome do elevador do ânus}

Critério diagnóstico;

Critérios de sintomas para proctalgia crônica e desconforto doloroso durante tração posterior no músculo puborretal.

\section{F2a2. Dor anorretal funcional inespecífica}

Critério diagnóstico:

Critérios de sintoma para proctalgia crônica, mas sem desconforto doloroso durante a tração posterior no músculo puborretal.

\section{F2b. Proctalgia fugaz}

Os critérios* diagnósticos devem incluir todos os itens a seguir:

1. Episódios recorrentes de dor localizada no ânus ou no reto baixo;

2. Os episódios duram de segundos a minutos;

3. Ausência de dor anorretal entre os episódios;

Para propósitos de pesquisa, os critérios devem ser preenchidos por 3 meses; entretanto, o diagnóstico clínico e a avaliação devem ter sido feitos antes de 3 meses.

\section{F3. Distúrbios funcionais da defecação}

Critérios diagnósticos*

1. O paciente deve satisfazer os critérios diagnósticos para constipação funcional ${ }^{* *}$;

2. Durante tentativas repetidas de defecar deve haver pelo menos dois dos seguintes itens:

a. Evidência de incapacidade de evacuação, baseada no teste de expulsão do balão ou por exames de imagem;

b. Contração inadequada dos músculos do assoalho pélvico (por exemplo, do esfíncter anal ou do puborretal) ou menos de $20 \%$ de relaxamento da pressão esfincteriana 
de repouso, avaliada por manometria, exame de imagem ou eletromiografia (EMG);

c. Força propulsiva evacuatória inadequada, avaliada por manometria ou exames de imagem;

* Critérios preenchidos nos últimos 3 meses com início dos sintomas pelo menos 6 meses antes do diagnóstico.

** Critério diagnóstico para constipação funcional:

(1) Deve incluir dois ou mais dos seguintes itens: (a) esforço evacuatório aumentado durante pelo menos $25 \%$ das defecações, (b) Fezes grumosas ou duras em pelo menos 25\% das defecações, (c) Sensação de evacuação incompleta em pelo menos 25\% das defecações, (d) Sensação de obstrução /bloqueio anorretal em pelo menos $25 \%$ das defecações, (e) Manobras manuais para facilitar pelo menos $25 \%$ das defecações (por exemplo, evacuação com ajuda digital, apoio do assoalho pélvico), (f) Menos de três defecações por semana.
(2) Fezes moles raramente estão presentes sem o uso de laxantes. (3) Existem critérios insuficientes para síndrome do intestino irritável.

\section{F3a. Defecação dissinérgica}

Critério diagnóstico*

Contração inapropriada dos músculos do assoalho pélvico ou menos de $20 \%$ de relaxamento da pressão esfincteriana basal em repouso, com força propulsiva adequada durante tentativa de evacuação

\section{F3b. Propulsão defecatória inadequada}

Critério diagnóstico*

Força propulsiva inadequada com ou sem contração inapropriada ou menos de $20 \%$ de relaxamento esfincteriano anal durante tentativa de defecação. 